\title{
PDA Stent: Unique Challenge in the Cardiac Catheterization Laboratory
}

\author{
Tuan-Yen Wu* \\ Department of Anesthesiology, China Medical University \\ and Hospital, Taiwan \\ *Correspondling author: Tuan-Yen Wu, Department \\ of Anesthesiology, China Medical University and \\ Hospital, Taiwan
}

Received: April 20, 2018; Accepted: May 09, 2018; Published: May 16, 2018

\begin{abstract}
As technology improves, more and more pediatric patients with cardiac abnormalities are receiving minimally invasive procedures in cardiac catheterization laboratories. However, because of their pathophysiology and procedure types, these patients bear special risks and pose unique challenges to anesthesiologists. The author presents a patient with pulmonary atresia with an intact ventricular septum (PA/IVS) who underwent placement of a Patent Ductus Arteriosus (PDA) stent and balloon valvotomy. Cardiopulmonary resuscitation was performed due to stent dislodgement into main pulmonary trunk.
\end{abstract}

Keywords: Pulmonary Atresia with Intact Ventricular Septum (PA/IVS); Patent Ductus Arteriosus (PDA) Stent; Cardiac Catheterization; Anesthesia

\section{Case Presentation}

A 4-day-old male was born to a 33-year-old mother by cesarean section at gestational age $35+2$ weeks, with a birth body weight of $2760 \mathrm{gm}$. Antepartum examination suggested that fetus pulmonary atresia was present. After birth, the infant exhibited fair activity but $\mathrm{O}_{2}$ saturation remained only around $90 \%$, even when given $3 \mathrm{~L} / \mathrm{min}_{2}$ via nasal cannula. Dyspnea, substernal retraction, and tachypnea with a significant systolic heart murmur over the left upper sternal border were noted. He was sent to neonatal intensive care unit for further treatment. Echocardiography showed pulmonary atresia Figure 1 and a large patent ductus arteriosus (PDA) [under prostaglandin E1 (PGE1) 3ng $/ \mathrm{kg} / \mathrm{min}$ ] (Figure 2). After proper preoperative evaluation and discussion, the patient's family agreed to initial PDA stenting and transcatheter perforation of the pulmonary valve in the cardiac catheterization laboratory. Conscious sedation was intended. After administering intravenous midazolam $0.3 \mathrm{mg}$, the cardiologists prepared vascular access via the left femoral vein and right femoral artery. After introducing a guide wire and injecting contrast agent into the descending artery, severe bradycardia developed, accompanied by worsened desaturation. Angiography showed a severe PDA spasm (Figure 3). The neonate was immediately intubated and mechanically ventilated. Attempts to perforate the pulmonary valve failed several times, thus the cardiologist decided to stent the PDA first (Figure 3). However, after deployed the PDA stent, they attempted balloon valvotomy several times. During the procedure, cardiopulmonary function abruptly collapsed and resuscitation ensued. Angiography showed PDA stent embolization into the main pulmonary artery. Attempts to retrieve the stent failed. The patient was sent to the operating room for stent retrieval and surgical valvuloplasty. The subsequent surgery was uneventful, but the patient ultimately died of severe lung complications.

\section{Discussion}

Pulmonary atresia with an intact ventricular septum (PA/IVS) is a duct-dependent cyanotic congenital heart disease. As deoxygenated blood courses via the inferior and superior vena cava to the right atrium, it does not pass through the tricuspid valve to the right ventricle; instead, the majority of the blood volume is diverted via the patent foramen ovale (PFO) or atrial septal defect (ASD) to the left atrium, then into the systemic circulation. Deoxygenated blood is shunted away from the pulmonary circulation because of highly elevated right ventricular pressure, resulting from the atretic pulmonary valve. To oxygenate the blood, a patent ductus arteriosus (PDA) is essential, connecting systemic to pulmonary oxygenation. Patients with PA/ IVS are cyanotic at birth. Initial palliative care includes PGE1 infusion to keep the ductus arteriosus open, pulmonary valvotomy, and/or modified Blalock-Taussig shunt; definitive repair is typically deferred [1]. As cardiac catheterization techniques improve, stenting the PDA and balloon valvotomy appear to be effective alternatives and are minimally invasive [2]. PDA stenting was even shown to be superior for promoting even pulmonary vasculature growth, compared to a modified Blalock-Taussig shunt [3]. Therefore, it is prudent for anesthesiologists to become familiar with the procedure and its possible complications when caring for these patients perioperatively.

Periprocedural risks were significantly elevated in our patient. The Improving Pediatric and Adult Congenital Treatment (IMPACT) Registry-derived risk models predict adverse cardiac events associated with interventional or diagnostic catheterization for congenital heart diseases [4]. The overall periprocedural morbidity and mortality was approximately $7 \%$ in this heterogeneous group. Patients younger than 30 days old have an odds ratio of 1.43 compared to those older than 30 days. Procedure types were divided into 6 categories; stenting for PDA and perforation of the atresic pulmonary valve were classified as Category 5 procedures, with procedures featuring a high odds ratio of approximately 8 as Category 1 procedures (myocardial biopsy). Hemodynamic vulnerability with systemic saturation $<95 \%$ adds additional risks, compared to those without hemodynamic markers. Thus, cardiac catheterization laboratory anesthesiologists should be more vigilant when taking care of similar pediatric patients.

Periprocedural management centered around the balance between systemic to pulmonary blood flow as well as RV functional support. Acidosis, hypoxemia, hypercapnia, vasoconstrictive drugs,
Austin J Anesthesia and Analgesia - Volume 6 Issue 1 - 2018 ISSN : 2381-893X | www.austinpublishing group.com Wu. @ All rights are reserved
Citation: Tuan-Yen Wu. PDA Stent: Unique Challenge in the Cardiac Catheterization Laboratory. Austin J Anesthesia and Analgesia. 2018; 6(1): 1069. 


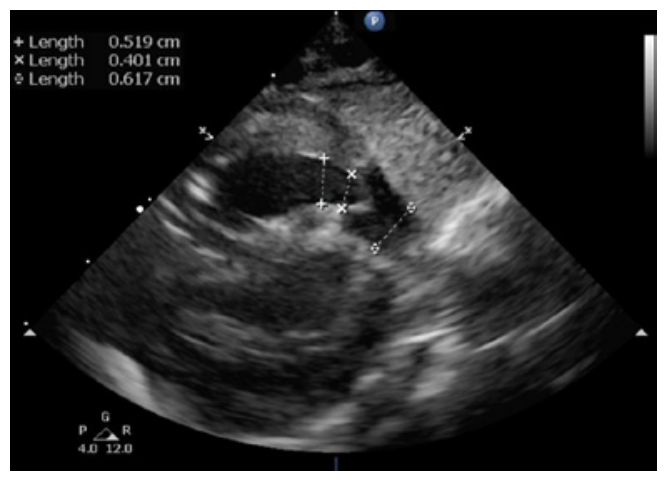

Figure 1: Atretic dome-shaped pulmonary valve.

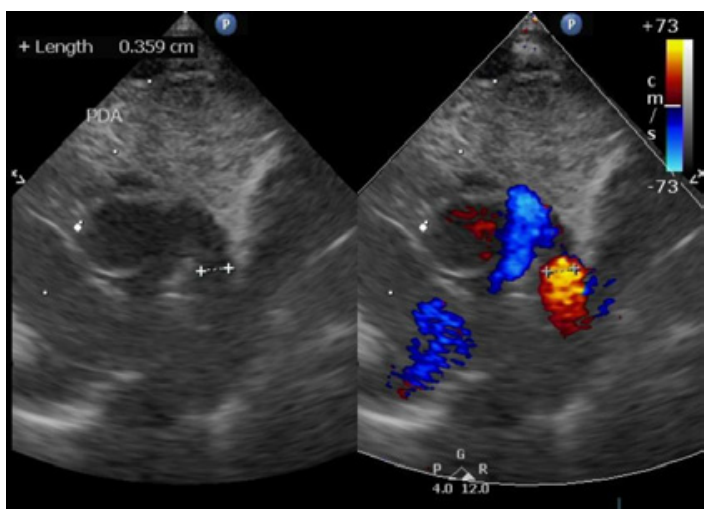

Figure 2: Large PDA, $0.359 \mathrm{~cm}$ in width.

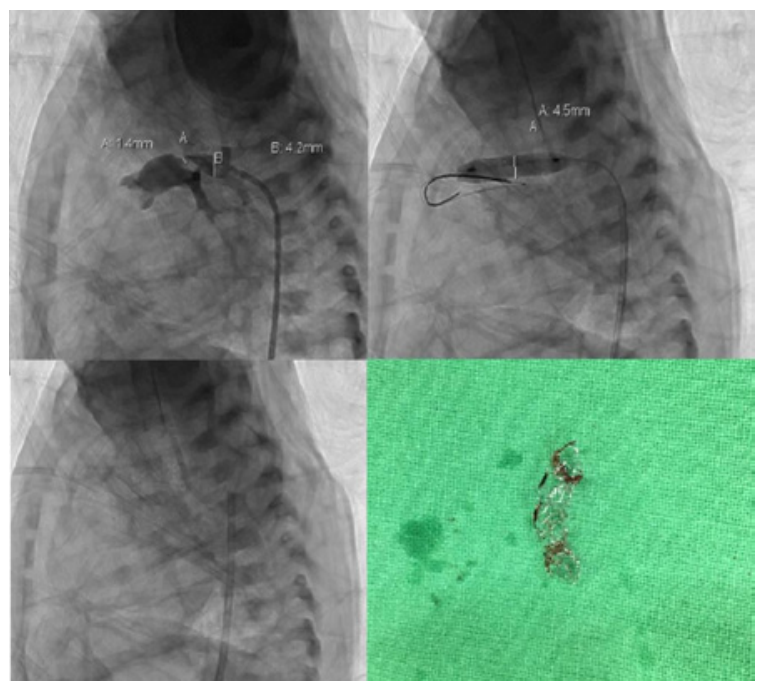

Figure 3: Acute PDA spasm with desaturation (Left-Upper). PDA stent deployment (Right-Upper). Deployed PDA stent (Left-Lower). Retrieved PDA stent after open-heart surgery (Left-Lower).

and atelectasis all contribute to increasing pulmonary vascular resistance (PVR). To date, there has been insufficient data regarding the best type of anesthesia for pediatric patients undergoing diagnostic or therapeutic cardiac catheterization [5]. From a physiologic perspective, general anesthesia with controlled ventilation might provide better $\mathrm{pH}$ balance, while mechanical ventilation poses more burden to the already-vulnerable cardiovascular system. Conscious sedation carries a risk of airway obstruction but avoids the need for tracheal intubation, potentially resulting in faster recovery.

PDA stent dislodgement is an uncommon complication. In the past literature, there were only sporadic case reports covering PDA stent migration. Michel-Behnke I. and colleagues [6] reported one dislocation to the left main pulmonary artery followed by successful resuscitation. Hussain A, and colleagues [7] found two that dislodged to the right pulmonary artery and Schranz D, et al [8] reported one; all three were converted to surgical aorto-pulmonary shunts. Alwi M, and colleagues [9] reported one to the left femoral artery and Matter $\mathrm{M}$, et al [10] further covered one to the left pulmonary artery. Newly deployed stents can easily migrate distally, with the blood flow, or proximally following guide wire retrieval. In the current patient, it is deduced that to perform pulmonary valvotomy procedure, the guide wire went from the descending aorta to the pulmonary artery via the ductus arteriosus and rubbed against the stent, causing subsequent migration. The obstructed pulmonary trunk mimics an acute pulmonary embolism and requires immediate cardiopulmonary resuscitation.

\section{Conclusion}

Pediatric patients with PA/IVS are at increased perioperative risk associated with interventional cardiac catheterization procedures. Anesthesiologists should acquaint themselves with the unique pathophysiological changes and stratify the periprocedural managements tethered to each patient.

\section{References}

1. Yoshimura N, Yamaguchi M. Surgical strategy for pulmonary atresia with intact ventricular septum: Initial management and definitive surgery. Gen Thorac Cardiovasc Surg. 2009; 57: 338-346.

2. Chubb H, Pesonen E, Sivasubramanian S, Tibby SM, Simpson JM, Rosenthal $\mathrm{E}$, et al. Long-term outcome following catheter valvotomy for pulmonary atresia with intact ventricular septum. J Am Coll Cardiol. 2012; 59: 14681476.

3. Santoro G, Capozzi G, Caianiello G, Palladino MT, Marrone C, Farina G, et al. Pulmonary artery growth after palliation of congenital heart disease with duct-dependent pulmonary circulation: Arterial duct stenting versus surgical shunt. J Am Coll Cardiol. 2009; 54: 2180-2186.

4. Jayaram N, Spertus JA, Kennedy KF, Vincent R, Martin GR, Curtis JP, et al. Modeling Major Adverse Outcomes of Pediatric and Adult Patients With Congenital Heart Disease Undergoing Cardiac Catheterization: Observations From the NCDR IMPACT Registry (National Cardiovascular Data Registry Improving Pediatric and Adult Congenital Treatment). Circulation. 2017; 136: 2009-2019.

5. Odegard KC, Vincent R, Baijal RG, Daves SM, Gray RG, Javois AJ, et al. SCAI/CCAS/SPA Expert Consensus Statement for Anesthesia and Sedation Practice: Recommendations for Patients Undergoing Diagnostic and Therapeutic Procedures in the Pediatric and Congenital Cardiac Catheterization Laboratory. Anesth Analg. 2016; 123: 1201-1209.

6. Michel-Behnke I, Akintuerk H, Thul J, Bauer J, Hagel KJ, Schranz D. Stent implantation in the ductus arteriosus for pulmonary blood supply in congenital heart disease. Catheter Cardiovasc Interv. 2004; 61: 242-252.

7. Hussain A, Al-Zharani S, Muhammed AA, Al-Ata J, Galal OM. Midterm outcome of stent dilatation of patent ductus arteriosus in ductal-dependent pulmonary circulation. Congenit Heart Dis. 2008; 3: 241-249.

8. Schranz D, Michel-Behnke I, Heyer R, Vogel M, Bauer J, Valeske K, et al. Stent implantation of the arterial duct in newborns with a truly duct-dependent pulmonary circulation: A single-center experience with emphasis on aspects 
of the interventional technique. J Interv Cardiol. 2010; 23: 581-588.

9. Alwi M, Choo KK, Latiff HA, Kandavello G, Samion H, Mulyadi MD. Initial results and medium-term follow-up of stent implantation of patent ductus arteriosus in duct-dependent pulmonary circulation. J Am Coll Cardiol. 2004; 44: 438-445.
10. Matter M, Almarsafawey H, Hafez M, Attia G, Abuelkheir MM. Patent ductus arteriosus stenting in complex congenital heart disease: Early and midterm results for a single-center experience at children hospital, Mansoura, Egypt. Pediatr Cardiol. 2013; 34: 1100-1106.
Austin J Anesthesia and Analgesia - Volume 6 Issue 1 - 2018

ISSN : 2381-893X | www.austinpublishinggroup.com

Wu. (c) All rights are reserved
Citation: Tuan-Yen Wu. PDA Stent: Unique Challenge in the Cardiac Catheterization Laboratory. Austin J Anesthesia and Analgesia. 2018; 6(1): 1069 